Check for updates

Cite this: Phys. Chem. Chem. Phys., 2017, 19, 23154

Received 6th June 2017,

Accepted 2nd August 2017

DOI: $10.1039 / c 7 c p 03798 h$

rsc.li/pccp

\title{
Excess charge driven dissociative hydrogen adsorption on $\mathrm{Ti}_{2} \mathrm{O}_{4}{ }^{-} \dagger$
}

\author{
Xiaowei Song, ${ }^{\text {ab }}$ Matias R. Fagiani, (D) ab Sreekanta Debnath, ${ }^{a b}$ Min Gao, ${ }^{c}$ \\ Satoshi Maeda, (D) C Tetsuya Taketsugu, (D) cd Sandy Gewinner, ${ }^{\text {c }}$ \\ Wieland Schöllkopf, (DD ${ }^{b}$ Knut R. Asmis (D) *a and Andrey Lyalin (D) *d
}

\begin{abstract}
The mechanism of dissociative $\mathrm{D}_{2}$ adsorption on $\mathrm{Ti}_{2} \mathrm{O}_{4}{ }^{-}$, which serves as a model for an oxygen vacancy on a titania surface, is studied using infrared photodissociation spectroscopy in combination with density functional theory calculations and a recently developed single-component artificial force induced reaction method. $\mathrm{Ti}_{2} \mathrm{O}_{4}{ }^{-}$readily reacts with $\mathrm{D}_{2}$ under multiple collision conditions in a gas-filled ion trap held at $16 \mathrm{~K}$ forming a global minimum-energy structure $\left(\mathrm{DO}-\mathrm{Ti}-(\mathrm{O})_{2}-\mathrm{Ti}(\mathrm{D})-\mathrm{O}\right)^{-}$. The highly exergonic reaction proceeds quasi barrier-free via several intermediate species, involving heterolytic $\mathrm{D}_{2}$-bond cleavage followed by $\mathrm{D}$-atom migration. We show that, compared to neutral $\mathrm{Ti}_{2} \mathrm{O}_{4}$, the excess negative charge in $\mathrm{Ti}_{2} \mathrm{O}_{4}{ }^{-}$is responsible for the substantial lowering of the $D_{2}$ dissociation barrier, but does not affect the molecular $D_{2}$ adsorption energy in the initial physisorption step.
\end{abstract}

\section{Introduction}

Titanium oxides are among the best candidates for heterogeneous photocatalysis. ${ }^{1-3}$ Numerous studies have been devoted to the investigation of their role in promoting water splitting. ${ }^{4-7}$ Hydrogenation of $\mathrm{TiO}_{2}$ nanomaterials significantly improves their solar-driven photocatalytic performance by reducing their band gap. ${ }^{8,9}$ However, the nature of the adsorbed hydrogen and the electronic structure at the surface remain subject to intense debate.

While $\mathrm{H}_{2}$ only weakly interacts with crystalline $\mathrm{TiO}_{2}$ surfaces, surface defects in the form of oxygen vacancies act as electron donors, providing specific adsorption sites at which molecular hydrogen can dissociatively adsorb. ${ }^{10}$ The removal of an oxygen atom formally leaves behind two unpaired electrons. The localization and mobility of these electrons have remained controversial. ${ }^{11,12}$ Density functional theory (DFT) calculations reveal that this excess charge is mainly localized on the surface 5-fold coordinated ${ }^{5 \mathrm{c}} \mathrm{Ti}$ atoms and/or 6-fold coordinated subsurface ${ }^{6 \mathrm{c}} \mathrm{Ti}$

\footnotetext{
${ }^{a}$ Wilhelm-Ostwald-Institut für Physikalische und Theoretische Chemie, Universität Leipzig, Linnéstrasse 2, D-04103 Leipzig, Germany. E-mail: knut.asmis@uni-leipzig.de

${ }^{b}$ Fritz-Haber-Institut der Max-Planck-Gesellschaft, Faradayweg 4-6, D-14195 Berlin, Germany

${ }^{c}$ Department of Chemistry, Faculty of Science, Hokkaido University, Sapporo 060-0810, Japan

${ }^{d}$ Global Research Center for Environment and Energy based on Nanomaterials Science (GREEN), National Institute for Material Science (NIMS), 1-1 Namiki, Tsukuba 305-0044, Japan. E-mail: LYALIN.Andrey@nims.go.jp

$\dagger$ Electronic supplementary information (ESI) available: TOF mass spectrum, minimum-energy structures, evolution of the orbital energies and calculated harmonic vibrational frequencies. See DOI: $10.1039 / \mathrm{c} 7 \mathrm{cp} 03798 \mathrm{~h}$
}

atoms in the vicinity of the defect, see ref. 11-13 and references therein. The degree of delocalization and the position of the reduced $\mathrm{Ti}$ atoms, often referred to as " $\mathrm{Ti}^{3+}$ centers", strongly depend on the level of theory used.

A localized excess charge can also originate from $\mathrm{OH}$ groups on $\mathrm{TiO}_{2}$ and indeed hydrogenated $\mathrm{TiO}_{2}$ shows considerably higher reaction rates for water splitting than a noble metal decorated $\mathrm{TiO}_{2}$ surface and also absorbs visible light in a broader spectral region. ${ }^{8,14,15}$ A recent study identified negatively-charged hydridetype $\mathrm{H}$-Ti species as the photoactive species, whose formation and stability are closely related to available surplus electrons on the rutile $\mathrm{TiO}_{2}(110)$ surface from oxygen vacancies or by the formation of surface hydroxyls. ${ }^{16}$ Isolated gas-phase clusters can serve as a model system for studying adsorption reactions at the molecular level with the key advantage of being amenable to high-level quantum chemical calculations. ${ }^{17-19}$ Here, we characterize the influence of the excess electron in the gas phase cluster $\mathrm{Ti}_{2} \mathrm{O}_{4}{ }^{-}$ on the mechanism of dissociative hydrogen adsorption using cryogenic ion vibrational spectroscopy in combination with DFT calculations and the recently developed single-component artificial force induced reaction (SC-AFIR) method. ${ }^{20}$

The stability and structure of titanium oxide clusters in the gas phase have been studied experimentally using VUV-ionization, ${ }^{21}$ collision induced dissociation, ${ }^{22,23}$ UV-photodissociation ${ }^{24}$ and ion mobility ${ }^{25}$ mass spectrometry as well as anion photoelectron, ${ }^{26-28}$ infrared resonance-enhanced multi-photon ionization ${ }^{29}$ and infrared photodissociation ${ }^{30,31}$ spectroscopy. These studies mainly focused on the characterization of $\left(\mathrm{TiO}_{2}\right)_{n}{ }^{+/ 0 /-}$ clusters $(n=1,2, \ldots)$, in particular the stability, vibrational frequencies and electron affinities of the smaller clusters and how these properties differ 
compared to those of the bulk as a function of the cluster size $n$. The structure of $\mathrm{Ti}_{2} \mathrm{O}_{4}{ }^{-}$was studied in more detail using slow electron velocity-map imaging (SEVI) anion photoelectron spectroscopy. ${ }^{28}$ Similar to neutral $\mathrm{Ti}_{2} \mathrm{O}_{4}$ it exhibits a non-planar $\mathrm{O}-\mathrm{Ti}-(\mathrm{O})_{2}-\mathrm{Ti}-\mathrm{O}$ motif containing a four-membered ring. ${ }^{32}$ However, the additional negative charge leads to stabilization of the $C_{2 \mathrm{v}}$ isomer over the $C_{2 \mathrm{~h}}$ structure in the negative ion. The gas phase reactivity of titanium oxide clusters is less well studied experimentally and their characterization has been limited to reactions with molecular oxygen ${ }^{33}$ and water. ${ }^{34}$

Computationally, the geometries of neutral and charged $\left(\mathrm{TiO}_{2}\right)_{n}$ clusters have been extensively investigated at both DFT and CCSD(T) levels of theory. ${ }^{28,31,35-42}$ Reactions of titanium oxide clusters with hydrogen and water have also been examined. ${ }^{34,43-47}$ As the number of $\mathrm{TiO}_{2}$ units $n$ in $\left(\mathrm{TiO}_{2}\right)_{n}{ }^{+/ 0 /-}$ clusters is increased, the number of isomers grows dramatically. This complicates the identification of low-energy structures and advanced algorithms for performing global minimum searches are required. As a result, conflicting structural assignments have been reported for smaller $\left(\mathrm{TiO}_{2}\right)_{n}$ clusters, with the latest study showing that up to $n=13$ the lowest energy structures do not contain a six-fold coordinated ${ }^{6 \mathrm{c}} \mathrm{Ti}$-atom characteristic of a $\mathrm{TiO}_{2}$ bulk crystal. ${ }^{39}$

Comparable difficulties arise, even for smaller titanium oxide clusters, when the mechanism of a chemical reaction with a molecular reactant at a finite temperature is investigated. The number of the possible reaction pathways similarly increases dramatically with size and complexity of the reactants, necessitating the consideration of an ensemble of energetically favorable isomers and possible rearrangements of the cluster structure during the reaction. Here, we make use of a fully automated method for systematically locating the reaction pathways among various isomers in order to unravel the molecular-level reaction mechanism. ${ }^{20}$ The future application of the present methodology to $\left(\mathrm{TiO}_{2}\right)_{n}{ }^{-}$ for larger $n$ is, in principle, straightforward.

\section{Methods}

\section{Experimental section}

Infrared photodissociation (IRPD) experiments were conducted on an ion trap tandem mass spectrometer described previously. ${ }^{48,49}$ $\mathrm{Ti}_{2} \mathrm{O}_{4}{ }^{-}$clusters are produced using a Smalley-type laser-vaporization source. $^{50}$ The second harmonic output (532 nm) of a $50 \mathrm{~Hz}$ Nd:YAG laser (Litron, Nano $\mathrm{S}$ ) is focused ( $25 \mathrm{~cm}$ focal length) onto the surface of a rotating and translating titanium rod. The plasmacontaining $\mathrm{Ti}$ atoms are entrained in a pulse of $0.75 \% \mathrm{O}_{2}$ seeded in He carrier gas ( 6 bar backing pressure) and expanded through a clustering channel held at $270 \mathrm{~K}$. The best ion signal stability was obtained for a turning speed of the rod of $\sim 3$ turns per min, laser pulse energies of up to $\sim 10 \mathrm{~mJ}$ and a time delay between firing of the laser and opening of the pulsed valve of $\sim 500 \mu \mathrm{s}$. The pulsed expansion passes through a $4 \mathrm{~mm}$ diameter skimmer. The anion beam is then collimated in a decapole ion-guide filled with He gas and mass-selected using a quadrupole mass-filter. Mass-selected anions are accumulated in a linear radio-frequency (RF) ring-electrode ion-trap held at $16 \mathrm{~K}$ and continuously filled with $\mathrm{D}_{2}$ gas. Trapped ions are internally cooled by collisions with the $\mathrm{D}_{2}$ gas. Physisorbed, i.e. messenger-tagged, and chemisorbed species are stabilized via three-body collisions. ${ }^{51}$

After loading the trap for $198 \mathrm{~ms}$, all ions are extracted and focused both temporally and spatially into the center of the extraction region of an orthogonally-mounted linear time-of-flight (TOF) mass spectrometer. Here, the ion packet is irradiated with a single macropulse ( $\sim 10 \mu$ s pulse length) from the free electron laser FHI-FEL operated at $5 \mathrm{~Hz}$ with a spectral bandwidth of $c a$. $0.2 \%$ (root mean square) of the central wavelength and pulse energies of $\sim 0.1$ to $2 \mathrm{~mJ} .{ }^{52}$ Subsequently, high voltage extraction pulses are applied and a TOF mass spectrum is recorded. IRPD spectra are obtained by simultaneously monitoring the depletion of the messenger-tagged (parent) ions and the formation of the bare (fragment) ions as a function of the IR radiation wavenumber, which was scanned in the spectral ranges $400-1300 \mathrm{~cm}^{-1}$ and $2000-3000 \mathrm{~cm}^{-1}$ in steps of $3 \mathrm{~cm}^{-1}$. 30 TOF mass spectra are summed at each wavenumber step. Each IRPD spectrum is averaged over three individual scans. The relative photodissociation cross section $\sigma_{\text {IRPD }}$ is determined as described previously. ${ }^{53,54}$

\section{Computational details}

All the stable structures and reaction pathways were searched systematically using the artificial force induced reaction (AFIR) method implemented in a local developmental version of the GRRM program ${ }^{55}$ with the potential energy gradient calculated using Guassian09. ${ }^{20,56}$ Within the AFIR approach the tentative products and transition states are obtained by applying an artificial force to randomly distributed reactants. ${ }^{20}$ The accurate final products and transition states are determined by reoptimization along the AFIR path using the locally updated plane $\operatorname{method}^{57}$ without artificial force and confirmed using the intrinsic reaction coordinate calculations. ${ }^{58}$ This strategy has been successfully used as a promising tool for the prediction of the reactivity of small metal clusters in the regime of fluxional structures and searching for favorable paths for single bond activation reactions. ${ }^{59,60}$

DFT calculations for adsorption and dissociation of $\mathrm{D}_{2}$ on $\mathrm{Ti}_{2} \mathrm{O}_{4}{ }^{-}$were performed at the UB3PW91/aug-cc-pVDZ level. ${ }^{61}$ The method and basis set were chosen based on a careful evaluation of previous work. ${ }^{62}$ All energies are calculated by considering the free energy correction at $T=70 \mathrm{~K}$, the estimated upper limit for the average temperature of the clusters probed in the experiment $(30-70 \mathrm{~K})$. The search for the dissociation pathways is done using the multi-component (MC)-AFIR method with a model collision energy parameter of $200 \mathrm{~kJ} \mathrm{~mol}^{-1}$. After the initial D-D bond breaking, the intermediates containing atomic D species are searched with the use of the single-component AFIR (SC-AFIR) method with a model collision energy parameter of $100 \mathrm{~kJ} \mathrm{~mol}^{-1}$ to get to the bottom of the local funnel for $\mathrm{DTi}_{2} \mathrm{O}_{4}{ }^{-}$ and $\mathrm{DTi}_{2} \mathrm{O}_{4} \mathrm{D}^{-}$. The present SC-AFIR method has been successfully used in our previous work for searching the most stable structures of dissociated $\mathrm{H}_{2}$ on small gold clusters $\mathrm{Au}_{n}(n=2-11) .{ }^{59,60}$ IR spectra are generated by convoluting the corresponding stick spectra derived from harmonic frequencies (no scaling) and 
intensities using a Gaussian line shape function with a FWHM of $10 \mathrm{~cm}^{-1}$. The influence of anharmonic effects on the vibrational frequencies was checked and was found to be small.

\section{Results and discussion}

$\mathrm{Ti}_{2} \mathrm{O}_{4}{ }^{-}$reacts readily with $\mathrm{D}_{2}$ under multiple collision conditions in the ion trap held at $16 \mathrm{~K}$ to form $\left[\mathrm{Ti}_{2} \mathrm{O}_{4} \mathrm{D}_{2}\right]^{-}$:

$$
\mathrm{Ti}_{2} \mathrm{O}_{4}^{-}+\mathrm{D}_{2} \stackrel{\mathrm{D}_{2}, T_{\text {Trap }}=16 \mathrm{~K}}{\longrightarrow}\left[\mathrm{Ti}_{2} \mathrm{O}_{4} \mathrm{D}_{2}\right]^{-}
$$

A typical TOF mass spectrum of the reaction products is shown in Fig. $\mathrm{S} 1$ of the ESI. $\dagger$ The $\left[\mathrm{Ti}_{2} \mathrm{O}_{4} \mathrm{D}_{2}\right]^{-}$anions do not dissociate under typical single photon absorption conditions, suggesting that the $\mathrm{D}_{2}$ molecule is involved in a barrierless (or low-barrier) reaction with a chemisorbed species, which is subsequently stabilized by three-body collisions.

In the following, we characterize the structure of $\left[\mathrm{Ti}_{2} \mathrm{O}_{4} \mathrm{D}_{2}\right]^{-}$ and elucidate the underlying reaction mechanism using DFT calculations. The IRPD spectrum of $\mathrm{D}_{2}$-tagged $\left[\mathrm{Ti}_{2} \mathrm{O}_{4} \mathrm{D}_{2}\right]^{-}$is shown in the bottom panel of Fig. 1. It is obtained by monitoring the photodissociation yield of the complexes containing additional, weakly bound $\mathrm{D}_{2}$ molecules, i.e. $\left[\mathrm{Ti}_{2} \mathrm{O}_{4} \mathrm{D}_{2}\right]^{-} \cdot\left(\mathrm{D}_{2}\right)_{1-3}$, as a function of the irradiation wavenumber. These complexes show the typical behavior of messenger-tagged anions and readily dissociate under single photon absorption conditions. The spectrum reveals eight characteristic peaks, labeled a to $\mathrm{h}$ in Fig. 1, and clearly shows poor agreement with the simulated spectrum of the entrance-channel complex $\mathrm{Ti}_{2} \mathrm{O}_{4}{ }^{-} \cdot \mathrm{D}_{2}$, labeled as $\mathbf{I}_{\text {cis }}$ in Fig. 1, supporting the notion that the first $\mathrm{D}_{2}$ molecule chemisorbs to $\mathrm{Ti}_{2} \mathrm{O}_{4}{ }^{-}$.

In order to identify the structure of $\left[\mathrm{Ti}_{2} \mathrm{O}_{4} \mathrm{D}_{2}\right]^{-}$we performed an extensive minimum-energy structure search using the SC-AFIR method. $14\left[\mathrm{Ti}_{2} \mathrm{O}_{4} \mathrm{D}_{2}\right]^{-}$isomers were identified. The lowest energy isomers are those, in which $\mathrm{D}_{2}$ dissociatively adsorbs to $\mathrm{Ti}_{2} \mathrm{O}_{4}{ }^{-}$, yielding structures in which one $\mathrm{D}$ atom is bound to an $\mathrm{O}$ atom and the other to a Ti atom (see $\mathbf{P}_{\mathbf{1}}$ to $\mathbf{P}_{\mathbf{5}}$ in Fig. 1). Higher energy isomers are shown in the ESI $\dagger$ (see Fig. S2). All low-lying isomers shown in Fig. 1 share the four-membered $\mathrm{Ti}-(\mathrm{O})_{2}-\mathrm{Ti}$ ring motif, also found in bare $\mathrm{Ti}_{2} \mathrm{O}_{4}{ }^{-28} \cdot{ }^{28}$ The isomers $\mathbf{P}_{\mathbf{1}}$ to $\mathbf{P}_{\mathbf{5}}$ all contain a Ti-hydroxide (Ti-OD) and a titanium hydride (Ti-D) bond involving the same $\left(\mathbf{P}_{\mathbf{4}}\right.$ and $\left.\mathbf{P}_{5}\right)$ or different Ti atoms $\left(\mathbf{P}_{\mathbf{1}}-\mathbf{P}_{3}\right)$. Moreover, the $\mathbf{P}_{2} / \mathbf{P}_{3}$ and $\mathbf{P}_{\mathbf{4}} / \mathbf{P}_{5}$ structures represent pairs with identical connectivity, i.e., they are conformational isomers and are thus rather close in energy.

The simulated IR spectra of $\mathbf{P}_{\mathbf{1}}$ to $\mathbf{P}_{\mathbf{5}}$ are also shown in Fig. 1. Best agreement with the experimental IRPD spectrum of $\left[\mathrm{Ti}_{2} \mathrm{O}_{4} \mathrm{D}_{2}\right]^{-} \cdot\left(\mathrm{D}_{2}\right)_{1-3}$ is obtained for the lowest energy isomer $\mathbf{P}_{\mathbf{1}}$, which allows assignments of the eight experimental features a to $\mathrm{h}$ to fundamental transitions involving predominantly stretching modes (see Table 1). The three highest energy bands a to $\mathrm{c}$, found at $2790 \mathrm{~cm}^{-1}, 1071 \mathrm{~cm}^{-1}$ and $956 \mathrm{~cm}^{-1}$, are the $\mathrm{O}-\mathrm{D}, \mathrm{Ti}-\mathrm{D}$ and terminal $\mathrm{Ti}=\mathrm{O}$ stretching modes, respectively. The triplet $\mathrm{d}$ to $\mathrm{f}$, observed in-between $850 \mathrm{~cm}^{-1}$ and $550 \mathrm{~cm}^{-1}$, is characteristic of the $\mathrm{Ti}-(\mathrm{O})_{2}-\mathrm{Ti}$ four-membered ring, as has been previously observed in related systems. ${ }^{63,64}$ This ring consists of a three-fold-coordinated $\left({ }^{3 \mathrm{c}} \mathrm{Ti}\right)$ and a four-fold-coordinated

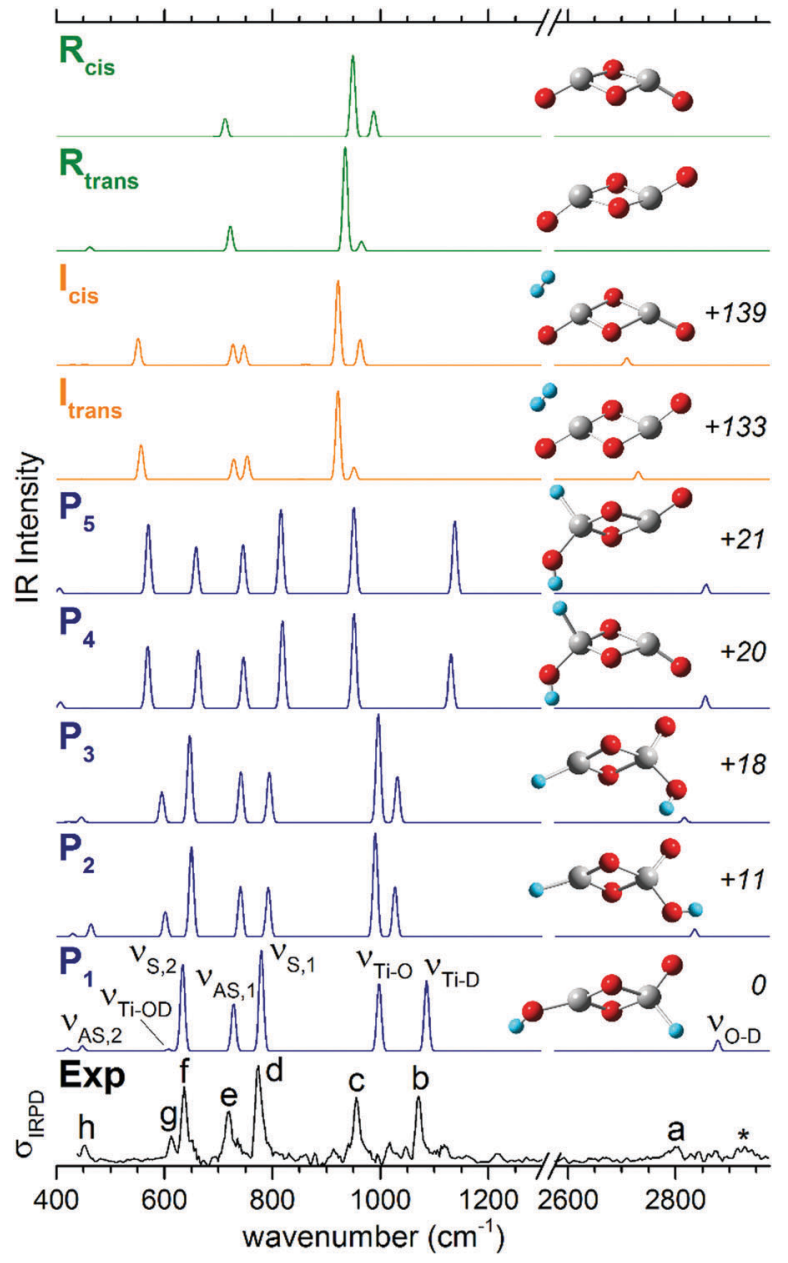

Fig. 1 Experimental IRPD spectrum of $\left[\mathrm{Ti}_{2} \mathrm{O}_{4} \mathrm{D}_{2}\right]^{-} \cdot\left(\mathrm{D}_{2}\right)_{1-3}$ (bottom panel) and unscaled UB3PW91/aug-cc-pVDZ harmonic IR spectra (upper panels) of low energy isomers of bare $\mathrm{Ti}_{2} \mathrm{O}_{4}{ }^{-}\left(\mathbf{R}_{\text {cis }}\right.$ and $\left.\mathrm{R}_{\text {trans }}\right), \mathrm{Ti}_{2} \mathrm{O}_{4}{ }^{-}\left(\mathrm{D}_{2}\right)$ (physisorbed, $I_{c i s}$ and $I_{\text {trans }}$ ) and $\left[\mathrm{Ti}_{2} \mathrm{O}_{4} \mathrm{D}_{2}\right]^{-}$(chemisorbed, $\mathbf{P}_{1}-\mathrm{P}_{\mathbf{5}}$ ) in the fingerprint $\left(400-1300 \mathrm{~cm}^{-1}\right)$ and $O-D$ stretching $\left(2575-2975 \mathrm{~cm}^{-1}\right)$ spectral regions. Assignments of the IR-active vibrational modes are indicated ( $\nu$ : stretching, $\nu_{\mathrm{s}} / \nu_{\text {as }}$ : symmetric/antisymmetric $\mathrm{Ti}-(\mathrm{O})_{2}$ stretching of the $\mathrm{Ti}-(\mathrm{O})_{2}-\mathrm{Ti}$ ring, ' 1 ' and ' 2 ' refer to the 3 - and 4 -fold coordinated Ti-atom, respectively). ' $*$ ' denotes weak adsorption assigned to the $D_{2}$ stretching mode. See Table 1 and Table S1 (ESI $\dagger$ ) for band positions and assignments. Minimum-energy structures ( $\mathrm{R}$ : reactant, I: intermediate, $\mathrm{P}$ : product; $\mathrm{Ti}=$ silver, $\mathrm{O}=$ red, $\mathrm{H}=$ turquoise) and relative energies (in $\mathrm{kJ} \mathrm{mol}^{-1}$ ) are shown on the right of each panel.

Ti atom $\left({ }^{4 \mathrm{c}} \mathrm{Ti}\right)$. The four intracyclic Ti-O single bonds combine to two sets of symmetric $\left(\nu_{\mathrm{s}}\right)$ and antisymmetric $\left(\nu_{\mathrm{as}}\right)$ stretching modes involving the $\mathrm{O}-{ }^{3 \mathrm{c}} \mathrm{Ti}-\mathrm{O}\left(\nu_{\mathrm{s}, 1}, \nu_{\mathrm{as}, 1}\right)$ and $\mathrm{O}-{ }^{4 \mathrm{c}} \mathrm{Ti}-\mathrm{O}\left(\nu_{\mathrm{s}, 2}, \nu_{\mathrm{as}, 2}\right)$ moiety, respectively. These four modes correspond to bands $\mathrm{d}, \mathrm{e}$, $\mathrm{f}$ and $\mathrm{h}$ in the experimental IRPD spectrum. Finally, band $\mathrm{g}$ is assigned to the Ti-OD stretching mode.

While the simulated spectra of the energetically higher-lying isomers $\mathbf{P}_{\mathbf{2}}$ to $\mathbf{P}_{\mathbf{5}}$ are rather similar to that of $\mathbf{P}_{\mathbf{1}}$, which can be expected, due to the similar structures, there are some characteristic differences, which disfavor an assignment to these higher energy structures. First, the spacing $\left(115 \mathrm{~cm}^{-1}\right)$ and relative intensities of the $\mathrm{Ti}-\mathrm{D}$ and $\mathrm{T}=\mathrm{O}$ stretching modes (bands b and c in Fig. 1) are best reproduced by the spectrum 
Table 1 Experimental band positions (in $\mathrm{cm}^{-1}$ ), calculated harmonic vibrational frequencies (in $\mathrm{cm}^{-1}$ ) and IR Intensities (in parentheses, in $\mathrm{km} \mathrm{mol}^{-1}$ ) of $\left[\mathrm{Ti}_{2} \mathrm{O}_{4} \mathrm{D}_{2}\right]^{-}$

\begin{tabular}{llrc}
\hline Band & Mode $^{a}$ & Exp. & UB3PW91 \\
\hline$*$ & $\nu(\mathrm{D}-\mathrm{D})$ & 2927 & \\
$\mathrm{a}$ & $\nu(\mathrm{O}-\mathrm{D})$ & 2790 & $2877(53)$ \\
$\mathrm{b}$ & $\nu(\mathrm{Ti}-\mathrm{D})$ & 1071 & $1086(340)$ \\
$\mathrm{c}$ & $\nu(\mathrm{Ti}=\mathrm{O})$ & 956 & $997(325)$ \\
$\mathrm{d}$ & $\nu_{\mathrm{s}}{ }^{\left.3{ }^{3} \mathrm{Ti}-(\mathrm{O})_{2}\right)}$ & 773 & $779(485)$ \\
$\mathrm{e}$ & $\nu_{\mathrm{as}}{ }^{\left.3{ }^{3} \mathrm{Ti}-(\mathrm{O})_{2}\right)}$ & 719 & $727(227)$ \\
$\mathrm{f}$ & $\nu_{\mathrm{s}}\left({ }^{4 \mathrm{~T}} \mathrm{Ti}-(\mathrm{O})_{2}\right)$ & 636 & $634(416)$ \\
$\mathrm{g}$ & $\nu(\mathrm{Ti}-\mathrm{OD})$ & 613 & $610(13)$ \\
$\mathrm{h}$ & $\left.\nu_{\mathrm{as}}{ }^{4} \mathrm{C} \mathrm{Ti}-(\mathrm{O})_{2}\right)$ & 452 & $449(25)$ \\
& $\delta(\mathrm{Ti}-\mathrm{D})$ & & $420(14)$
\end{tabular}

${ }^{a}$ Stretching $(\nu)$, bending $(\delta)$, symmetric (s), antisymmetric (as).

of $\mathbf{P}_{\mathbf{1}}\left(89 \mathrm{~cm}^{-1}\right)$. In the other spectra the spacing is either predicted too small $\left(\mathbf{P}_{2}: 37 \mathrm{~cm}^{-1}, \mathbf{P}_{3}: 35 \mathrm{~cm}^{-1}\right)$ or too large $\left(\mathbf{P}_{4}: 179 \mathrm{~cm}^{-1}, \mathbf{P}_{5}: 187 \mathrm{~cm}^{-1}\right)$. Second, the relative position and intensities of bands $d$ to $g$ are best reproduced by the spectrum of $\mathbf{P}_{\mathbf{1}}$ and much less satisfactorily by the spectra of $\mathbf{P}_{\mathbf{2}}$ to $\mathbf{P}_{5}$.

The reaction path for reaction (1) is shown in Fig. 2 and the most relevant structures are shown in Fig. 3. The reaction starts out from the $C_{2 \mathrm{v}}$ ground state structure $\mathbf{R}_{\text {cis }}$ (see Fig. 3) of the reactant $\mathrm{Ti}_{2} \mathrm{O}_{4}{ }^{-62}$ The corresponding trans-isomer $\mathbf{R}_{\text {trans }}$ of $C_{\mathrm{s}}$ symmetry lies slightly higher in energy, also at $70 \mathrm{~K}$, where the difference in free energy amounts to only $0.3 \mathrm{~kJ} \mathrm{~mol}^{-1}$ (B3PW91/aug-cc-pVDZ). Therefore, these two isomers likely co-exist under the current experimental conditions. Moreover, the barrier between $\mathbf{R}_{\text {cis }}$ and $\mathbf{R}_{\text {trans }}$ is small $\left(3.0 \mathrm{~kJ} \mathrm{~mol}^{-1}\right)$ and they can readily isomerize. Higher energy isomers are shown in the ESI $\dagger$ (see Fig. S3).

In the first step, the $\mathrm{D}_{2}$ molecule can either physisorb to $\mathbf{R}_{\boldsymbol{c} \text { is }}$ or $\mathbf{R}_{\text {trans }}$, forming the intermediates $\mathbf{I}_{\text {cis }}$ and $\mathbf{I}_{\text {trans }}$, respectively. The formation of $\mathbf{I}_{\text {trans }}$ is energetically favored (adsorption energies: $-9.6 \mathrm{~kJ} \mathrm{~mol}^{-1}$ vs. $-4.6 \mathrm{~kJ} \mathrm{~mol}^{-1}$ ). Subsequently, the $\mathrm{D}_{2}$ molecule in $\mathbf{I}_{\text {trans }}$ dissociates via $\mathrm{TS}_{\mathrm{a}}^{\text {trans }}$, which lies $5.7 \mathrm{~kJ} \mathrm{~mol}^{-1}$ above $\mathbf{I}_{\text {trans }}$ but substantially below the free energy of the entrance channel. This leads to the formation of the product $\mathbf{P}_{5}$, in which one of the $\mathrm{D}$ atoms remains bound to the Ti atom and the other migrates to the adjacent terminal O-atom forming a hydroxyl group. In the case of intermediate $\mathbf{I}_{\boldsymbol{c} i \boldsymbol{s}}, \mathrm{D}_{2}$ dissociates via $\mathrm{TS}_{\mathrm{a}}^{\text {cis }}$ (4.6 $\mathrm{kJ} \mathrm{mol}^{-1}$ above $\mathbf{I}_{\text {cis }}$ ) forming product $\mathbf{P}_{4}$, which can further cis-trans isomerize to $\mathbf{P}_{5}$ via $\mathbf{T S}_{4-5}$ with a barrier of $3.0 \mathrm{~kJ} \mathrm{~mol}^{-1}$. Alternatively, $\mathbf{I}_{\boldsymbol{c i s}}$ can isomerize to $\mathbf{I}_{\text {trans }}$ through the complicated pathway over transition states $\mathrm{TS}^{\prime}, \mathrm{TS}^{\prime \prime}$, and $\mathrm{TS}^{\prime \prime \prime}$ with free energies of 7.2, 10.3 and $6.1 \mathrm{~kJ} \mathrm{~mol}^{-1}$, respectively. This isomerization is, however, partially suppressed, because it is energetically less favorable compared to the direct dissociation of $\mathrm{D}_{2}$ on $\mathbf{I}_{\text {cis }}$.

Subsequently, $\mathbf{P}_{5}$ can isomerize to the global minimumenergy product $\mathbf{P}_{\mathbf{1}}$ via $\mathbf{T S}_{\mathbf{b}}$, which involves the migration of a $\mathrm{D}$ atom from one Ti atom to the other. Considering that we only observe $\mathbf{P}_{\mathbf{1}}$ and not $\mathbf{P}_{\mathbf{4}, 5}$ as products suggests that even though the isomerization barrier $\mathbf{P}_{\mathbf{5}} \rightarrow \mathbf{P}_{\mathbf{1}}$ is relatively high $\left(66.9 \mathrm{~kJ} \mathrm{~mol}^{-1}\right)$, this exergonic reaction is not kinetically hindered, probably due to the absence of rapid-cooling of the ions on the time scale of the reaction.

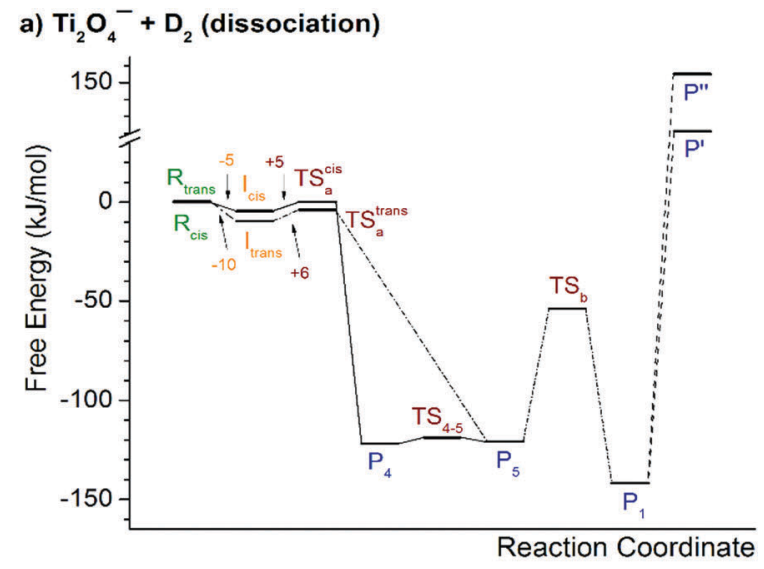

b) $\mathrm{Ti}_{2} \mathrm{O}_{4}^{-}+\mathrm{D}_{2}$ (isomerization)
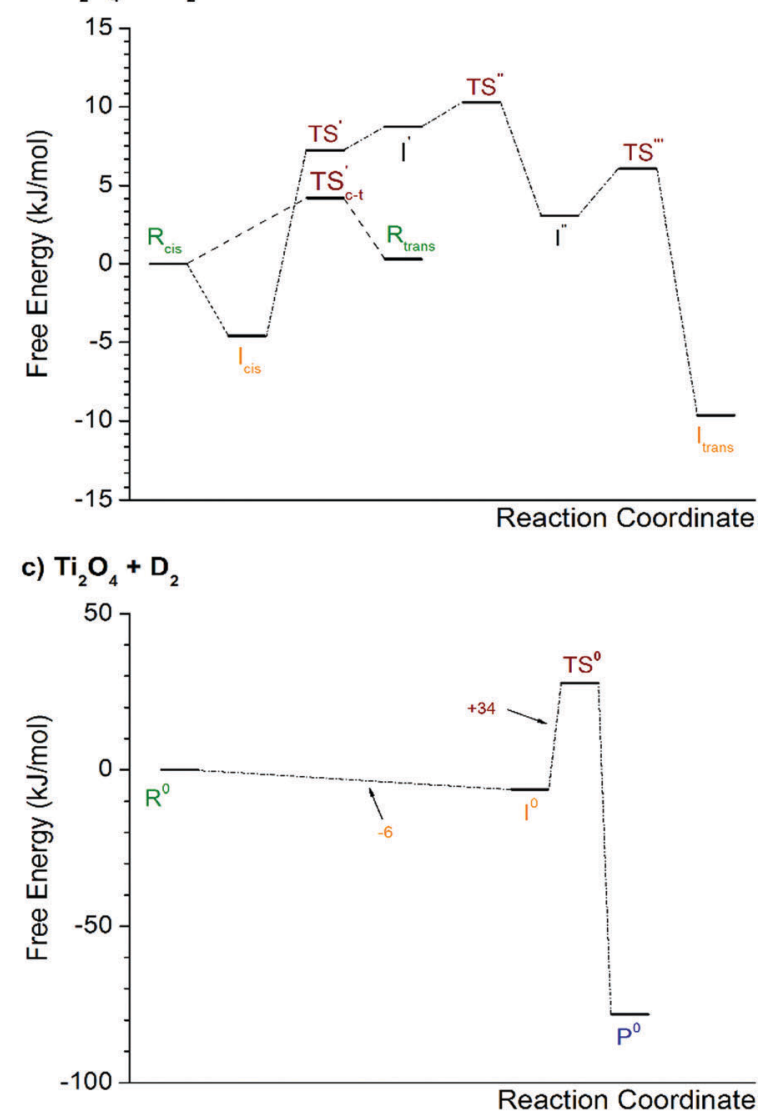

Fig. 2 Full free-energy profile $(70 \mathrm{~K}, 1 \mathrm{~atm})$ for the most favorable path for $\mathrm{D}_{2}$ dissociation on the cis- (solid line) and trans- (dashed dotted line) isomers of anionic $\mathrm{Ti}_{2} \mathrm{O}_{4}{ }^{-}$clusters (a); cis-trans isomerization pathways for anionic $\mathrm{Ti}_{2} \mathrm{O}_{4}{ }^{-}$(dashed line) and $\left[\mathrm{Ti}_{2} \mathrm{O}_{4} \mathrm{D}_{2}\right]^{-}$(dashed dotted line) clusters (b); and $\mathrm{D}_{2}$ dissociation path on the neutral $\mathrm{Ti}_{2} \mathrm{O}_{4}$ cluster (c).

$\mathbf{P}_{\mathbf{1}}$ is the most stable intermediate obtained by the SC-AFIR method. Removal of a $\mathrm{D}$ atom from $\mathbf{P}_{\mathbf{1}}$ leads to the formation of the $\left[\mathrm{Ti}_{2} \mathrm{O}_{4} \mathrm{D}\right]^{-}$ isomers $\mathbf{P}^{\prime}$ and $\mathbf{P}^{\prime \prime}$ (see Fig. 2a and 3), but this is energetically highly unfavorable, requiring at least $131 \mathrm{~kJ} \mathrm{~mol}^{-1}$.

Note, any autodetachment processes from the anions involved in the reaction mechanism under the present experimental reaction conditions can be safely neglected due to the high electron affinity of $\mathrm{Ti}_{2} \mathrm{O}_{4}$ of more than $1.7 \mathrm{eV} .{ }^{28}$ 
(a)

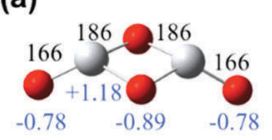

$\mathbf{R}_{\text {cis }}$

$+0.0$
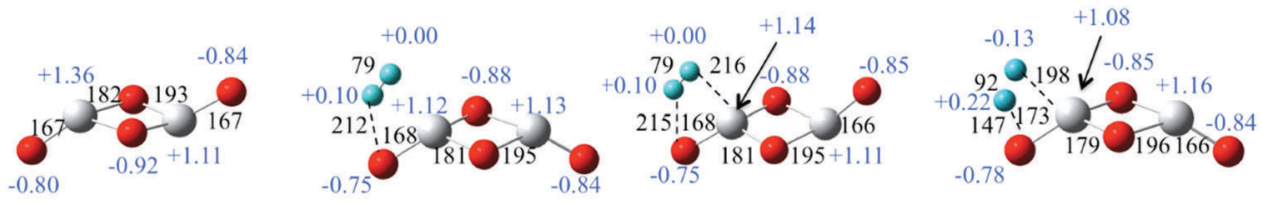

$$
\begin{gathered}
\mathbf{R}_{\text {trans }} \\
+0.3
\end{gathered}
$$
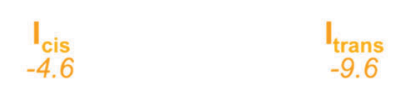

$\mathrm{TS}_{\mathrm{a}}{ }^{\text {cis }}$

$-3.9$
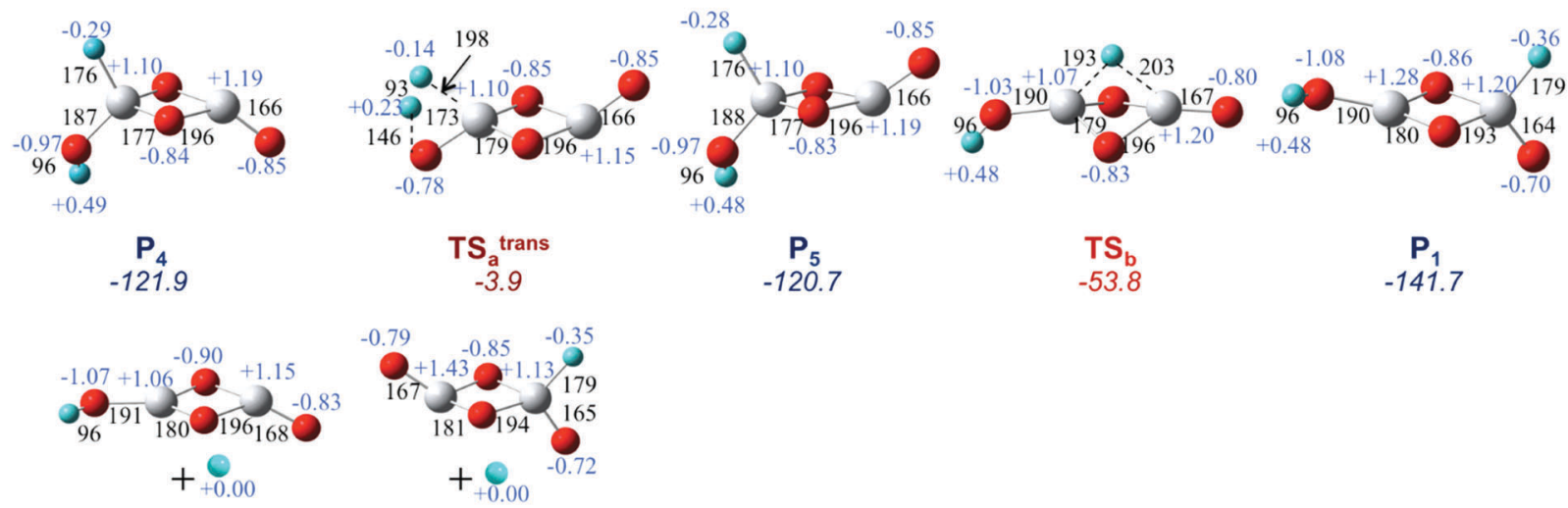

TS $_{\mathrm{b}}$
-53.8

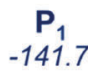

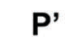

$+121.4$

(b)

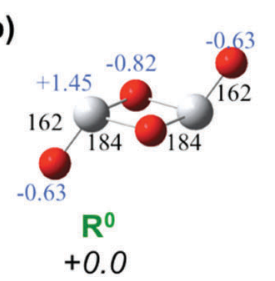

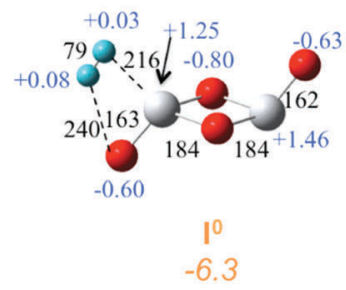

$-6.3$
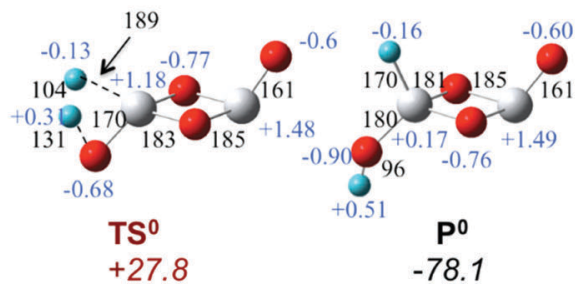

Fig. 3 Key structures along the dissociation path of $\mathrm{D}_{2}$ on $\mathrm{Ti}_{2} \mathrm{O}_{4}{ }^{-}$(a) and $\mathrm{Ti}_{2} \mathrm{O}_{4}$ (b) clusters. Free energies at $70 \mathrm{~K}$ (italic, in $\mathrm{kJ} \mathrm{mol}{ }^{-1}$ ), natural charges (blue, in $|e|$ ) and bond lengths (black, in pm) are also shown. $\mathrm{Ti}=$ grey, $\mathrm{Al}=$ pink, $\mathrm{O}=\mathrm{red}, \mathrm{H}=$ turquoise.

In order to understand the effect of the excess charge on the $\mathrm{D}_{2}$ dissociation we have also calculated the reaction pathway for $\mathrm{D}_{2}$ dissociation on neutral $\mathrm{Ti}_{2} \mathrm{O}_{4}$ (see Fig. 2c). The reaction starts out from the most stable structure, the trans isomer $\mathbf{R}^{\mathbf{0}}$ (see Fig. 3). The calculated adsorption energy of $\mathrm{D}_{2}$ to $\mathbf{R}^{\mathbf{0}}$ is $6.3 \mathrm{~kJ} \mathrm{~mol}^{-1}$, that is $3.3 \mathrm{~kJ} \mathrm{~mol}^{-1}$ less than for $\mathrm{D}_{2}$ adsorption to $\mathbf{R}_{\text {trans }}$ of the anion. However, in order for $\mathrm{D}_{2}$ to dissociate on the neutral cluster from $\mathbf{I}^{\mathbf{0}}$ via the transition state $\mathbf{T S}^{\mathbf{0}}$ (free energy: $27.8 \mathrm{~kJ} \mathrm{~mol}{ }^{-1}$ ) an energy of $34.1 \mathrm{~kJ} \mathrm{~mol}^{-1}$ (relative to $\mathbf{I}^{\mathbf{0}}$ ) is required. Hence, $\mathrm{D}_{2}$ dissociation on the neutral $\mathrm{Ti}_{2} \mathrm{O}_{4}$ cluster is energetically highly unfavorable. This result is in qualitative agreement with a previous prediction, where a barrier of $65 \mathrm{~kJ} \mathrm{~mol}^{-1}$ for $\mathrm{H}_{2}$ dissociation on $\mathrm{Ti}_{2} \mathrm{O}_{4}$ was obtained using the hybrid B3LYP functional. ${ }^{46}$

To obtain a deeper insight into the mechanism of $\mathrm{D}_{2}$ dissociation on $\mathrm{Ti}_{2} \mathrm{O}_{4}{ }^{-}$vs. $\mathrm{Ti}_{2} \mathrm{O}_{4}$ we computed the natural bond orbital (NBO) $)^{65}$ charge distribution on the relevant species along the dissociation pathways (see Fig. 3). The natural charges localized on the singly and doubly coordinated $\mathrm{O}$ atoms are $-0.78|e|$ and $-0.89|e|$, respectively, for the anionic $\mathbf{R}_{c i s}$ (Fig. 3a), and $-0.63|e|$ and $-0.82|e|$, respectively, for the neutral $\mathbf{R}^{\mathbf{0}}$
(Fig. 3b). Each Ti atom carries a positive natural charge of $+1.18|e|\left(\mathbf{R}_{c i s}\right)$ and $+1.45|e|\left(\mathbf{R}^{0}\right)$. Thus, in the anion $\mathbf{R}_{c i s}$ the extra electron is mainly localized on the Ti atoms and only partly on the (terminal) $\mathrm{O}$ atoms. The charge distribution in $\mathbf{R}_{\text {trans }}$ is not symmetric with charges on the two Ti atoms of $+1.36|e|$ and $+1.11|e|$, while the terminal $\mathrm{O}$ atoms carry a charge of $-0.80|e|$ and $-0.84|e|$. This charge distribution qualitatively resembles that of a defect on a $\mathrm{TiO}_{2}$ surface, where the formation of the $\mathrm{O}$ vacancy results in the reduction of the nearest Ti atom(s) and the localization of an excess charge in the vicinity of the defect.

Adsorption of molecular $\mathrm{D}_{2}$ on either $\mathrm{Ti}_{2} \mathrm{O}_{4}{ }^{-}$or $\mathrm{Ti}_{2} \mathrm{O}_{4}$ is accompanied initially by only a small $(\sim 0.1|e|)$ intermolecular charge-transfer from $\mathrm{D}_{2}$ to the corresponding cluster, but results in a substantial intramolecular charge redistribution in the cluster and partial reduction of the Ti atom interacting with $\mathrm{D}_{2}$ (see Fig. 3a and b). In the intermediate species $\mathbf{I}_{\text {trans }}$ and $\mathbf{I}^{\mathbf{0}}$, preceding $\mathrm{D}_{2}$ dissociation, the molecular $\mathrm{D}_{2}$ is slightly activated, evidenced by an elongated D-D bond (79 pm) compared to that of isolated $\mathrm{D}_{2}(76 \mathrm{pm})$. The reaction then proceeds via the transition states $\mathbf{T S}_{\mathbf{a}}$ and $\mathbf{T S}_{\mathbf{0}}$, respectively, in which the dissociating $\mathrm{D}_{2}$ is markedly polarized, containing a partially 


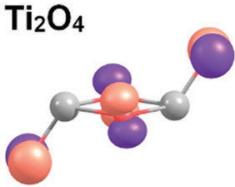

HOMO

$\mathrm{Ti}_{2} \mathrm{O}_{4}^{-}$(cis)
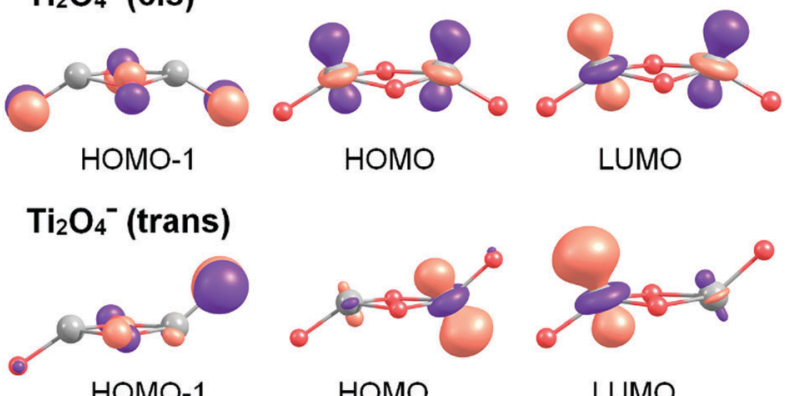

HOMO
LUMO

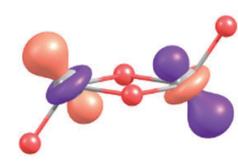

LUMO+1

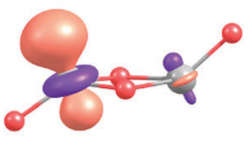

LUMO
Fig. 4 Highest occupied ( $\mathrm{HOMO}$ ) and lowest unoccupied molecular orbitals (LUMO) of neutral $\mathrm{Ti}_{2} \mathrm{O}_{4}\left(\mathbf{R}^{\mathbf{0}}\right)$ and anionic $\mathrm{Ti}_{2} \mathrm{O}_{4}{ }^{-}\left(\mathbf{R}_{\text {cis }}\right.$ and $\left.\mathbf{R}_{\text {trans }}\right)$.

positively $(>+0.2|e|)$ and a partially negatively $(>|-0.1| e||)$ charged D-atom. $\mathrm{D}_{2}$ then dissociates heterolytically into $\mathrm{D}^{\delta+}$ (Ti-OD) and $\mathrm{D}^{\delta-}(\mathrm{Ti}-\mathrm{D})$ species.

The substantially lower reaction barrier for $\mathrm{D}_{2}$ dissociation on the anion $\mathrm{Ti}_{2} \mathrm{O}_{4}{ }^{-}$compared to that on neutral $\mathrm{Ti}_{2} \mathrm{O}_{4}$ can be rationalized by examining the structure of the transition states $\mathbf{T S}_{\mathbf{a}}$ and $\mathbf{T S}^{\mathbf{0}}$ (see Fig. 3a and b). In the neutral system $\left(\mathbf{T S}^{\mathbf{0}}\right.$ ) the $\mathrm{D}_{2}$ molecule is required to approach the cluster closer, accompanied by stronger structural deformations, compared to the anion $\left(\mathbf{T S}_{\mathbf{a}}\right)$, which requires more energy and consequently makes $\mathrm{D}_{2}$ dissociation on the neutral $\mathrm{Ti}_{2} \mathrm{O}_{4}$ cluster energetically unfavorable.

Additional insights can be gained from a molecular orbital (MO) analysis. Fig. 4 shows the relevant frontier orbitals, such as the highest occupied molecular orbital (HOMO) and the lowest unoccupied molecular orbital (LUMO), for neutral and anionic $\mathrm{Ti}_{2} \mathrm{O}_{4}$ clusters. (The overall evolution of the orbital energies during dissociation of the $\mathrm{D}_{2}$ molecule on $\mathrm{Ti}_{2} \mathrm{O}_{4} v s$. anionic $\mathrm{Ti}_{2} \mathrm{O}_{4}{ }^{-}$is shown in Fig. S4 of the ESI. $\dagger$ ) The extra electron occupies the HOMO of $\mathrm{Ti}_{2} \mathrm{O}_{4}{ }^{-}$, an in-phase combination of the $3 \mathrm{~d}_{z^{2}}$ orbitals on the Ti atoms, which corresponds to the LUMO of the neutral $\mathrm{Ti}_{2} \mathrm{O}_{4}\left(\mathbf{R}^{\mathbf{0}}\right)$. In contrast, the HOMO of the neutral is delocalized over all O-atoms. This has two consequences. First, the anion is characterized by a substantially smaller HOMO-LUMO gap, with a HOMO that is well separated from all other occupied MOs (see Fig. S4, ESI $\dagger$ ). Second, the additional electron density on the metal centers in the anion has a stabilizing effect on heterolytic $\mathrm{D}_{2}$ dissociation (see Fig. 3). Interestingly, the HOMOs of the cis $\left(\mathbf{R}_{c i s}\right)$ and trans $\left(\mathbf{R}_{\text {trans }}\right)$ isomers of $\mathrm{Ti}_{2} \mathrm{O}_{4}{ }^{-}$are qualitatively different. While the HOMO of $\mathbf{R}_{c i s}$ is symmetrically delocalized over both Ti atoms, it is predominantly localized on a single Ti atom in $\mathbf{R}_{\text {trans }}$. This electron localization induced symmetry-breaking is reflected in the lower symmetry structure of $\mathbf{R}_{\text {trans }}$ (see Fig. 3a) and is favorable for the reaction with $\mathrm{D}_{2}$, which proceeds via the similarly asymmetric transition state $\mathrm{TS}_{\mathrm{a}}^{\text {trans }}$.

\section{Conclusions}

$\mathrm{D}_{2}$ dissociatively adsorbs on the gas phase cluster $\mathrm{Ti}_{2} \mathrm{O}_{4}{ }^{-}$even at cryogenic temperatures. The reaction is quasi barrier-free, proceeds heterolytically and leads to the formation of the global minimum-energy species (DO-Ti-(O) $\left.)_{2}-\mathrm{Ti}(\mathrm{D})-\mathrm{O}\right)^{-}$, which we identified using vibrational spectroscopy. DFT calculations predict that under similar conditions the reaction does not occur for neutral $\mathrm{Ti}_{2} \mathrm{O}_{4}$ clusters, due to the presence of a substantial activation barrier. The height of the activation barrier is directly related to the exergonicity of the reaction, which is roughly twice as large in the anion compared to the neutral system. Moreover, the additional charge in the (bare) anion leads to electron localization induced symmetry-breaking, similar to the previously reported cases in other metal oxide clusters such as $\mathrm{Al}_{2} \mathrm{O}_{4}{ }^{-}$and $\mathrm{V}_{8} \mathrm{O}_{20}{ }^{-63,66,67}$ As a result, the structural deformation of the $\mathrm{Ti}_{2} \mathrm{O}_{4}{ }^{-}$core during the dissociative adsorption of $\mathrm{D}_{2}$ is less pronounced compared to neutral $\mathrm{Ti}_{2} \mathrm{O}_{4}$ and hence the activation barrier is smaller too.

The $\mathrm{Ti}_{2} \mathrm{O}_{4}{ }^{-} / \mathrm{Ti}_{2} \mathrm{O}_{4}$ system represents a useful cluster model for studying some of the properties of charge defects on $\mathrm{TiO}_{2}$ surfaces. In addition, it can be used to test the applicability of approximations required for calculations on more extended systems (e.g. surface reactions). The limits of the present cluster model are also apparent. In order to mimic the presence of sixfold coordinated ${ }^{6 \mathrm{c}} \mathrm{Ti}$-centers, which are characteristic of $\mathrm{TiO}_{2}$ surfaces, much larger $\left(\mathrm{TiO}_{2}\right)_{n}{ }^{-}$clusters are required $(n>13) .{ }^{39}$ However, the application of the present methodology to these larger systems is, in principle, feasible.

\section{Acknowledgements}

This work was supported by the Collaborative Research Center 1109 of the German Research Foundation DFG, Japan Society for the Promotion of Science (JSPS KAKENHI Grants 15K05387 and 16KT0047) and by MEXT as "Priority Issue on Post-K computer" (Development of new fundamental technologies for highefficiency energy creation, conversion/storage and use). This work was partially supported by the MEXT program Development of Environmental Technology using Nanotechnology. The computations were partly performed at the Research Center for Computational Science, Okazaki, Japan and at the Numerical Materials Simulator at NIMS, Tsukuba, Japan. XS thanks the Alexander-von-Humboldt Foundation for a post-doctoral research fellowship. GM, TT and AL would like to thank Prof. Masato Kobayashi for fruitful discussions.

\section{Notes and references}

1 A. L. Linsebigler, G. Lu and J. T. Yates, Chem. Rev., 1995, 95, 735-758.

2 T. L. Thompson and J. T. Yates, Chem. Rev., 2006, 106, 4428-4453.

3 Q. Guo, C. Y. Zhou, Z. B. Ma, Z. F. Ren, H. J. Fan and X. M. Yang, Chem. Soc. Rev., 2016, 45, 3701-3730.

4 A. Fujishima and K. Honda, Nature, 1972, 238, 37-38. 
5 S. U. M. Khan, M. Al-Shahry and W. B. Ingler, Science, 2002, 297, 2243-2245.

6 A. Kudo and Y. Miseki, Chem. Soc. Rev., 2009, 38, 253-278.

7 M. G. Walter, E. L. Warren, J. R. McKone, S. W. Boettcher, Q. Mi, E. A. Santori and N. S. Lewis, Chem. Rev., 2010, 110, 6446-6473.

8 X. Chen, L. Liu, P. Y. Yu and S. S. Mao, Science, 2011, 331, 746-750.

9 X. B. Chen, L. Liu and F. Q. Huang, Chem. Soc. Rev., 2015, 44, 1861-1885.

10 W. Gopel, G. Rocker and R. Feierabend, Phys. Rev. B: Condens. Matter Mater. Phys., 1983, 28, 3427-3438.

11 P. M. Kowalski, M. F. Camellone, N. N. Nair, B. Meyer and D. Marx, Phys. Rev. Lett., 2010, 105, 146405.

12 S. Chretien and H. Metiu, J. Phys. Chem. C, 2011, 115, 4696-4705.

13 B. J. Morgan and G. W. Watson, Surf. Sci., 2007, 601, 5034-5041.

14 M. I. Nandasiri, V. Shutthanandan, S. Manandhar, A. M. Schwarz, L. Oxenford, J. V. Kennedy, S. Thevuthasan and M. A. Henderson, J. Phys. Chem. Lett., 2015, 6, 4627-4632.

15 T. Leshuk, R. Parviz, P. Everett, H. Krishnakumar, R. A. Varin and F. Gu, ACS Appl. Mater. Interfaces, 2013, 5, 1892-1895.

16 Z. Wu, W. Zhang, F. Xiong, Q. Yuan, Y. Jin, J. Yang and W. Huang, Phys. Chem. Chem. Phys., 2014, 16, 7051-7057.

17 K. R. Asmis, Phys. Chem. Chem. Phys., 2012, 14, 9270-9281.

18 J. Sauer and H.-J. Freund, Catal. Lett., 2015, 145, 109-125.

19 D. K. Böhme and H. Schwarz, Angew. Chem., Int. Ed., 2005, 44, 2336-2354.

20 S. Maeda, K. Ohno and K. Morokuma, Phys. Chem. Chem. Phys., 2013, 15, 3683-3701.

21 Y. Matsuda and E. R. Bernstein, J. Phys. Chem. A, 2005, 109, 314-319.

22 W. Yu and R. B. Freas, J. Am. Chem. Soc., 1990, 112, 7126-7133.

23 M. Velegrakis, M. Massaouti and M. Jadraque, Appl. Phys. A: Mater. Sci. Process., 2012, 108, 127-131.

24 M. Velegrakis and A. Sfounis, Appl. Phys. A: Mater. Sci. Process., 2009, 97, 765-770.

25 K. Ohshimo, N. Norimasa, R. Moriyama and F. Misaizu, J. Chem. Phys., 2016, 144, 194305.

26 H. Wu and L. S. Wang, J. Chem. Phys., 1997, 107, 8221-8228.

27 H.-J. Zhai and L.-S. Wang, J. Am. Chem. Soc., 2007, 129, 3022-3026.

28 J. B. Kim, M. L. Weichman and D. M. Neumark, J. Am. Chem. Soc., 2014, 136, 7159-7168.

29 K. Demyk, D. van Heijnsbergen, G. von Helden and G. Meijer, Astron. Astrophys., 2004, 420, 547-552.

30 E. Janssens, G. Santambrogio, M. Brümmer, L. Wöste, P. Lievens, J. Sauer, G. Meijer and K. R. Asmis, Phys. Rev. Lett., 2006, 96, 233401.

31 M. L. Weichman, X. W. Song, M. R. Fagiani, S. Debnath, S. Gewinner, W. Schöllkopf, D. M. Neumark and K. R. Asmis, J. Chem. Phys., 2016, 144, 124308.

32 Y. Gong, Q. Zhang and M. Zhou, J. Phys. Chem. A, 2007, 111, 3534-3539.
33 B. C. Guo, K. P. Kerns and A. W. Castleman, Int. J. Mass Spectrom., 1992, 117, 129-144.

34 S. Yin and E. R. Bernstein, Phys. Chem. Chem. Phys., 2014, 16, 13900-13908.

35 T. Albaret, F. Finocchi and C. Noguera, J. Chem. Phys., 2000, 113, 2238-2249.

36 Z. W. Qu and G. J. Kroes, J. Phys. Chem. B, 2006, 110, 8998-9007.

37 Z.-W. Qu and G.-J. Kroes, J. Phys. Chem. C, 2007, 111, 16808-16817.

38 W. Zhang, Y. Han, S. Yao and H. Sun, Mater. Chem. Phys., 2011, 130, 196-202.

39 M. Chen and D. A. Dixon, J. Chem. Theory Comput., 2013, 9, 3189-3200.

40 S. G. Neogi and P. Chaudhury, J. Comput. Chem., 2014, 35, 51-61.

41 Z. Zhang and J. T. Yates, Surf. Sci., 2016, 652, 195-199.

42 M. Calatayud, L. Maldonado and C. Minot, J. Phys. Chem. C, 2008, 112, 16087-16095.

43 L. B. Pandey and C. M. Aikens, J. Phys. Chem. A, 2012, 116, 526-535.

44 A. Valdes and G. J. Kroes, J. Phys. Chem. C, 2010, 114, 1701-1708.

45 T.-H. Wang, Z. Fang, N. W. Gist, S. Li, D. A. Dixon and J. L. Gole, J. Phys. Chem. C, 2011, 115, 9344-9360.

46 O. A. Syzgantseva, P. Gonzalez-Navarrete, M. Calatayud, S. Bromley and C. Minot, J. Phys. Chem. C, 2011, 115, 15890-15899.

47 M. Calatayud and C. Minot, J. Phys. Chem. C, 2009, 113, 12186-12194.

48 D. J. Goebbert, E. Garand, T. Wende, R. Bergmann, G. Meijer, K. R. Asmis and D. M. Neumark, J. Phys. Chem. A, 2009, 113, 7584-7592.

49 D. J. Goebbert, G. Meijer and K. R. Asmis, AIP Conf. Proc., 2009, 1104, 22-29.

50 T. Wende, PhD thesis, Freie Universitaet Berlin, 2012.

51 M. Brümmer, C. Kaposta, G. Santambrogio and K. R. Asmis, J. Chem. Phys., 2003, 119, 12700-12703.

52 W. Schöllkopf, S. Gewinner, H. Junkes, A. Paarmann, G. von Helden, H. Bluem and A. M. M. Todd, Proc. SPIE, 2015, 9512, 95121L.

53 N. Heine and K. R. Asmis, Int. Rev. Phys. Chem., 2015, 34, 1-34. 54 N. Heine and K. R. Asmis, Int. Rev. Phys. Chem., 2016, 35, 507. 55 S. Maeda, Y. Harabuchi, Y. Sumiya, M. Takagi, M. Hatanaka, Y. Osada, T. Taketsugu, K. Morokuma and K. Ohno, GRRM14 (A Developmental Version), Hokkaido University, 2016, see: http://grrm.chem.tohoku.ac.jp/GRRM/index_e.html.

56 M. J. Frisch, G. W. Trucks, H. B. Schlegel, G. E. Scuseria, M. A. Robb, J. R. Cheeseman, G. Scalmani, V. Barone, B. Mennucci, G. A. Petersson, H. Nakatsuji, M. Caricato, X. Li, H. P. Hratchian, A. F. Izmaylov, J. Bloino, G. Zheng, J. L. Sonnenberg, M. Hada, M. Ehara, K. Toyota, R. Fukuda, J. Hasegawa, M. Ishida, T. Nakajima, Y. Honda, O. Kitao, H. Nakai, T. Vreven, J. A. Montgomery Jr., J. E. Peralta, F. Ogliaro, M. J. Bearpark, J. Heyd, E. N. Brothers, K. N. Kudin, V. N. Staroverov, R. Kobayashi, J. Normand, 
K. Raghavachari, A. P. Rendell, J. C. Burant, S. S. Iyengar, J. Tomasi, M. Cossi, N. Rega, N. J. Millam, M. Klene, J. E. Knox, J. B. Cross, V. Bakken, C. Adamo, J. Jaramillo, R. Gomperts, R. E. Stratmann, O. Yazyev, A. J. Austin, R. Cammi, C. Pomelli, J. W. Ochterski, R. L. Martin, K. Morokuma, V. G. Zakrzewski, G. A. Voth, P. Salvador, J. J. Dannenberg, S. Dapprich, A. D. Daniels, Ö. Farkas, J. B. Foresman, J. V. Ortiz, J. Cioslowski and D. J. Fox, Gaussian 09, Gaussian, Inc., Wallingford, CT, USA, 2009.

57 C. Choi and R. Elber, J. Chem. Phys., 1991, 94, 751-760.

58 K. Fukui, Acc. Chem. Res., 1981, 14, 363-368.

59 M. Gao, A. Lyalin, S. Maeda and T. Taketsugu, J. Chem. Theory Comput., 2014, 10, 1623-1630.

60 M. Gao, A. Lyalin, M. Takagi, S. Maeda and T. Taketsugu, J. Phys. Chem. C, 2015, 119, 11120-11130.
61 T. H. Dunning, J. Chem. Phys., 1989, 90, 1007-1023.

62 S. G. Li and D. A. Dixon, J. Phys. Chem. A, 2008, 112, 6646-6666.

63 X. Song, M. R. Fagiani, S. Gewinner, W. Schöllkopf, K. R. Asmis, F. A. Bischoff, F. Berger and J. Sauer, J. Chem. Phys., 2016, 144, 244305.

64 K. R. Asmis, G. Meijer, M. Brümmer, C. Kaposta, G. Santambrogio, L. Wöste and J. Sauer, J. Chem. Phys., 2004, 120, 6461-6470.

65 A. E. Reed, L. A. Curtiss and F. Weinhold, Chem. Rev., 1988, 88, 899-926.

66 K. R. Asmis, G. Santambrogio, M. Brümmer and J. Sauer, Angew. Chem., Int. Ed., 2005, 44, 3122-3125.

67 M. Kaupp, A. Karton and F. A. Bischoff, J. Chem. Theory Comput., 2016, 12, 3796-3806. 